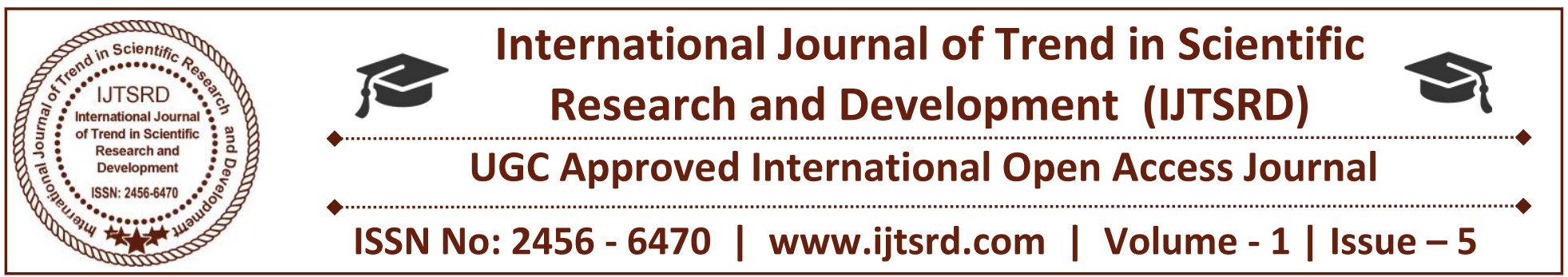

\title{
Co Variants and Adjustment of Disabled Children: A study in Elementary Schools in Uttar Pradesh
}

\author{
Singh, Ajay Kumar \\ Joint Director (SSA), SCERT, \\ Lucknow, Uttar Pradesh, India
}

\author{
Dr. Chhatrasal Singh \\ Reader Jawahar lal Nehru Smarak mahavidyalay, \\ Barabanki
}

\section{ABSTRACT}

Children with special need have difficulty in adjusting with their environment in many ways compared to their normal peers. Physical environment of schools, village/town and home is not conducive for CWSNs, as some need physical adjustment, some listening or communication and some observation or experiential adjustment. Due to these physical limitations, CWSNs are unable to actively participate in learning skills and knowledge effectively and become easy victim of teasing at public places. CWSN are not persons with different emotions, they just need special educational environment to grow like most of us. It has been found that CWSN, who may better adjust with physical, social and learning environment at home, school, public places with or without special devices, have better attendance at school. The disabled children have the same right to education, work and participation. These children with slight modification in their physical, social and educational environment may be transformed to outperformer in the area of their interest.

Keywords: Co Variants, adjustment, attendance, CWSN, and Elementary Schools In Uttar Pradesh.

\section{Introduction}

Children with disability should be educated, in the inclusive educational environment as sometime child with disability may not require any special educational need. These children are like other children in intellectual functionary. Humanity, realization and technology have opened new avenues of education for disabled children. Children with special needs should be given adequate physical and educational environment to develop and organize their life. They have much in common with other children of their age. They have many common aspects of child's development like: personality, the ability to communicate, resilience and strength, the ability to appreciate and enjoy life and the desire to learn. Each child has individual strengths, personality and experiences so particular disabilities will impact differently to individual children. They have all right to be the whole child, develop physically, socially, spiritually and mentally. They have right to education and dignified life. They have educational need, which sometimes may differ from non-disabled peers. Special educational needs may arise from primary four different types of disability: Physical, Sensory, Mental health, and Learning disability. They are not mentally diseased, they do have physical, visual or hearing problems, but they are otherwise like any other children and may be educated if physically and academically adjustable environment is provided. Number of problem arise due to disability i.e. Attention disorder, Memory problem, Reading problem, Listening problem, Movement problem, Reading disabled (vision), Writing disabled (physical), Adjustment problems.

For this study the common operational definition of disability has been used "The persons with disabilities in India has been defined by PWD Act, 1995" Ministry of law, justice and company affairs, 
promulgated this Act to give effect to the Proclamation on the Full Participation and Equality of the People with Disabilities in the Asian and Pacific Region, as adopted on $5^{\text {th }}$ December 1992 at Beijing. India being a signatory to the said proclamation considered it necessary to implement the aforesaid proclamation.

\section{Review of Literature}

Shigeki Fujii (2007) at National Institute of special Needs Education did a lot of research work on Lifelong support for individuals with special needs through Education, Social Welfare, Healthcare, Labor and Medical Care. Consideration was done from the view point of the support system by a Local Government. This research focused on ways in which the lifelong support system of people with special needs could be better delivered by examining the support system provided through the collaboration of specialists in the fields of education welfare, health care, labor, etc. It evaluated support for each life stage on an individual basis provided through coordination among related institutions and services as the core of a support system for individuals with special needs.

This research demonstrated that although support for each life stage pre-school age, the school age and the active working age, was provided before the establishment of this support system for individuals with special needs, support content at each stage was not properly communicated to the next stage, so the parents had to seek information regarding support at every stage. For such parents, the lack of support made it difficult to face the challenges confronting them on a daily basis. The Konkan city support system for individuals with special need facilitates the communication of individual teaching plans to the individuals in charge of each stage through local coordination by maintaining the continuity of support. Ted S. Hasselbring Candyce H. Williams Glaser, use of computer Technology to Help Students with Special Needs. This paper draws a picture of schools of USA, how technology may improve learning. Millions of students across the United States cannot benefit fully from a traditional educational program because they have a disability that impairs them to participate in a traditional classroom environment. For such students, computer based technologies can play an important role. Not only can computer technology facilitate a broader range of educational activities to meet a variety of needs for students with mild learning disorders, but also adaptive technology now exists that can enable even those students with severe disabilities to become active learners in the classroom alongside their peers who do not have disabilities. Computer technology has also enhanced the development of sophisticated devices that can assist such students with more server disabilities in overcoming a wide range of limitations that hinder classroom participation from speech and hearing impairments to blindness and severe physical disabilities.

However, many teachers are not adequately trained on how to use technology effectively in their classrooms, and the cost of the technology is a serious consideration for all schools. Computer technology has the potential to act as an equalizer by empowering students with disabilities. Need is to adequately train teachers and reduce cost so that schools or parents may bear it.

Wesley Sharpe, Ed.D. The characteristics of effective inclusion," How does inclusion benefit children who have disabilities?" this paper project education scene of United State with respect to children with special needs. "A generation ago, few classrooms in the United States included students with disabilities. As late as the middle of the 1970s, an estimated 1 million children with disabilities didn't even attend school," reported a May 1999 NEA Today Online cover story, "Inclusion Confusion." For disabled children who did attend school, special education usually meant placement in a special class or a special school. The problem with segregated special education is that "youngsters will not learn in segregated settings how to function in a non-disabled world," said Art Shapiro,

a professor of special education at Kean University and author of Everybody Belongs: Changing Negative Attitudes toward Classmates with Disabilities. At one point, the American Federation of Teachers even called for a moratorium on full inclusion. "We have great problems with the movement that says 'Start by putting all the children in the regular classroom,'. It's not inclusion if the supports are not in place," Shapiro told Education World. When supports are in place, there are many benefits worth considering. Shapiro listed the following four ways inclusion benefits disabled children:

$>$ Inclusion improves learning for both classified and non-classified students.

$>$ Children learn to accept individual differences.

$>$ Children develop new friendships. 
$>$ CWSN's Parent participation improves at general local schools.

$>$ It's a matter of civil rights for students with disabilities.

Caren Sax, Ian Pumpian, and Doug Fisher, San Diego State University researchers, discuss assistive technology in a research brief, Assistive Technology and Inclusion. Education experts warn that a wellequipped technology centre does not guarantee successful inclusion. Sometimes low-tech or lesssophisticated aids will meet a child's needs. Such simple accommodations as large-print books, preferential seating, behaviour-management programs, or modified desks may be sufficient for many children with disabilities. Before deciding on assistive devices, special educators should ask themselves the following questions:

> Has the student been involved in the selection process of Adjustable device?

$>$ Is the appropriate device as per target activity identified?

$>$ Can volunteers with specific "fix-it" skills may design adaptations?

John McDonnell believes that educators must resolve a number of significant issues before inclusive education become a reality. "Although there is a research base on school reform and systems change, the nuts and bolts of what schools should specifically be doing to make inclusion work is just emerging," he told Education World. These issues include:

$>$ The need to research for adjustable technology and curriculum.

$>$ The need to impart better pre-service teacher's training to serve all children.

$>$ The need to redesign teacher education programs.

According to McDonnell, the most effective inclusive classrooms have the following characteristics, Children are clustered in specific classes but distributed across all teachers, Students receive instructional supports that maximize their participation in the general education curriculum and their engagement in the general population, Teachers use a variety of strategies, including curriculum and instructional adaptations, peer tutoring, cooperative learning, and layered curriculum.

Dr. Kumar Sanjeev, Lecturer, P.G. Department of
Education Patna University, Bihar (INDIA) \& Dr. Khagendra Kumar Head Department of Education Patna University, Bihar (INDIA), India is one of the few countries worlds over where the education of children with special needs doesn't fall within the purview of human resource development ministry. It is generally the burden of the omnibus ministry of social justice and empowerment, the prime focus of which is rehabilitation, not education. Seventy eight percent of Indian population lives in rural areas without provision for special schools. Therefore, inclusive schools have to address the needs of all children in every community and have to train teachers to manage inclusive classrooms. Inclusive education (IE) is a new approach towards educating the children with disability and learning difficulties with that of normal ones within the same roof. It seeks to address the learning needs of all children with a specific focus on those who are vulnerable to marginalization and exclusion.

Inclusion is not an experiment to be tested but a value to be followed. All the children whether they are disabled or not have the right to education, as they are the future citizens of the country. In the prevailing Indian situation resources are insufficient even to provide quality mainstream schools for common children, it is unethical and impracticable to put children with special needs to test or to prove anything in a research study to live and learn in the mainstream of school and community.

Katharine Giffard-Lindsay, "Ignorance is a guarantee of marginalization". This paper highlights the educational problem of disabled children by putting worldwide not school going children's figure to approximately 113 million, and highlights the potential for education to reverse the negative effects of social exclusion. There were an estimated 25 million children out of school in India (MHRD 2003 statistics, cited in World Bank, 2004), many of whom are marginalized by dimensions such as poverty, gender, disability, and caste. While many educational programs have attempted to reach out to these previously excluded children, those with disabilities are often forgotten, emphasizing their invisible status in a rigidly categorized society.

This paper, while limited by the lack of available empirical data and constraints of desk research, aims to present a case study of the current status of inclusive education in India with a focus on children 
with disabilities. It explores access issues faced by children with disabilities in the first three zones of exclusion - those without any basic education access, those who drop-out after entry, and those who are at risk from exclusion.

The paper concludes that a twin-track approach to disability may assist not only in improving educational access for marginalized children, but also the reconceptualization of inclusive education as a school quality issue to benefit all children.

Asha Hans (Hans \& Patri, 2003: 5), "I live in a cocoon of social making Peeping out at the world from behind a curtain". This paper explain disability in global development, it not only raises questions of diverse local interpretations of the same issue, but also the need to accept the diversity of needs within the group, depending on both the nature of impairment and cultural\& local context.

In the UK, the medical model is reflected in the psycho-medical dominance of segregated education for children with disabilities in the 1950's (Clough \& Corbett, 2000), which was transported to developing contexts by colonialists and development agencies. This model can be seen, however, as being dominant long before the 1950's, with philanthropic, charitable institutions being set up from the mid-1800s in both north and south, particularly for blind or deaf children, by Christian missionaries. In India, the Ministry of Social Justice and Empowerment, which is responsible for people with disabilities, has a medically-inspired classification system whereby one's disability either falls into the category of locomotors, visual, hearing, speech or mental.

Children with disabilities are a secluded that is not prioritized in the context of education programs in India, although they are often found in many marginalized groups that are catered for if nondisabled? For example: girls, scheduled tribe, scheduled caste, and other backward caste children. Inclusive education may be a way of merging these children's needs in order to improve school quality and achieve EFA. The issues and constraints faced by the stakeholders involved, particularly for children with disabilities, lead to the conclusion that a twintrack approach to disability may assist not only in improving education access, but also the reconceptualization of inclusive education as a school quality issue.
Position Paper National Focus Group on Educationof Children with Special Needs, Dr. (Mrs.) Smriti Swarup (Chairperson), Director, Centre of Special Education SNDT Women's University and others. The paper discusses the issues relating to the provisions, practices and curricular concerning children with Special Educational Needs (CWSN) in India. Though CWSN may result from a number of factors, this paper is however, concerned with those arising from physical, sensory and intellectual disabilities.

Trends in provisions in India reflect that the leading policy predisposition before the 1970 s has been that of segregation. In the 1970s the IEDC scheme was launched by the Union government for providing educational opportunities to learners with CWSN in regular schools. Nevertheless, the statistics show that though the integration of learners with CWSN gathered some momentum, the coverage under this scheme remained inadequate. After the World Conference on Special Needs Education in Salamanca in 1990s, inclusion became the magic word in the educational field. The Salamanca Statement adopted by representatives of 92 Governments and 25 International Organizations has, in fact, set the policy agenda for inclusive education on a global basis. Inclusive education refers to all learners, young people with or without disabilities being able to learn together in ordinary pre-school provisions, schools and community educational settings with appropriate network of support services.

In addition to the provision of aids and appliances, a flexible, broad and balanced curriculum that can meet the needs of all children is the call of the day. The paper, therefore, proposes an inclusive curriculum for all students without discrimination on the basis of gender, ethnic origin, socio economic group, disability or ability.

The studies also make it clear that it is very important to understand how education of disabled children should be taken care of. What are the conditions to have inclusive education, which are the areas, where individual training is required? How different social and environmental issues affect education of disabled child. How should we modify our school environment to make it more inclusive, what are teacher's training needs to impart individualized education in an inclusive classroom. 


\section{Significance of the study}

Individuals are assessed usually as disabled after we feel that they have problem in understanding, communicating and receiving instructions in their day-to-day life and in school. A variety of tests are administered to ascertain type of disability and special need of such children. These test are not only to ascertain, how the child is differently abled than his/her peer but to ascertain which kind or type of academic support he/she needs to adjust in their working, living and learning environment, what kind of process, material and teaching intervention are needed for his/her unhindered learning, so that he/she may live a dignified life and may contribute to the society.

In this study significant effort have been made to establish adjustment related factors affecting education of disabled children. Efforts have been made to find out correlation between different parameters with student attendance in school i.e. Selfcare, Regular outing, Routine work, Social gathering, Playing games.

\section{Data and Method}

In order to know the teaching learning environment and the academic achievement of the children with special needs, visits were organized to see many bridge courses run by department of basic education of Uttar Pradesh. Schools were also visited, where children with special needs were studying in inclusive way. Some special schools run by non-government organizations were also visited to get a feeling of problems faced by these kinds of children in adjusting with routine daily personal work and education.

Teachers and warden of bridge courses, inclusive schools and special schools were consulted before making any research design. Their interaction was helpful in figuring out areas, which have greater impact on elementary education of children with special needs. On the basis of that research objectives and hypothesizes were constructed.

\section{Research Design}

The research design followed in the study is descriptive (survey) and evaluative. In this research the focus of the study is to test certain hypothesises regarding elementary education of CWSN at present. The descriptive survey method has been adopted primarily due to the fact that it facilitate in collecting general information and its one of the most commonly used method of investigation that attempts to describe and interpret what exists in the present conditions.

\section{Sample}

Sample has been taken carefully, so that results obtained from study of sample may be faithfully applied to the whole population. Following things are considered while selecting the sample.

$>$ There should be no partiality while selecting the sample.

> All major sub group of population should be sufficiently represented.

$>$ It should be manageable for completion of study.

In order to collect valid and reliable data about education status of CWSN a sample size of 500 (approximately 5\% of population) was set for the purpose. Size of sample for four different types of specially is Orthopaedic - 171, Visually Impaired 103, Hearing Impaired - 114, and Mentally Retarded - 107. In sample both the gender are adequately represented, Male- 252, Female - 258. In sample all social categories are sufficiently represented asScheduled caste- 187, other backward classes-199, General- 115. For this almost proportionate number of children were selected randomly from each kind of specially and population, to see effect of different kind of specialty on hypotheses.

Sampling: Sampling is a process used in statistical analysis in which a predetermined number of observations are taken from a larger population. Thus in the sampling technique instead of studying every unit of the universe, we study a sample drawn on some basis from the entire universe. In this study researcher has used stratified and purposive sampling. The sample should be a representative of entire population to get a representative sample, it should be ensured whether all elements are equally represented or not.

For the selection of sample the criterion followed was easy access to data, convenience in conducting survey, social structure and level of literacy. As per guidelines of Ministry of Human resource development all 20 blocks of district Allahabad are educationally backward, and being diverse in the sense of culture and education, it was selected for the purpose of study. Literacy rate of district Allahabad is 
$68 \%$. It has homogeneous population of all section of society.

As in literature there are 13-14 different types of disability in children. Even experts working in this area least understand and are able to diagnose only some of these disabilities. Children with some disability are very few in number as chances or probability of such disability is very rare. During visit of special schools, inclusive schools and bridge courses run by Government of Uttar Pradesh, we came to know, that majority of CWSN falls in category of Orthopaedic, Visually Impaired, Hearing impaired, and Mentally retarded. So for the purpose of study only these four types of CWSN have been taken in sample.

In this study different type of adjustment like selfcare, routine work, social gathering, and playing games has been studied. It has been also envisaged to see, how CWSN adjust with equipment and use equipment.

\section{Tools used for the study}

A format was developed for collecting data and information from different sources, Format has following elements for different kind of information.

$>$ Interview Schedule with child (CWSN).

$>$ Interview Schedule for the members of family.

$>$ Interview Schedule for the teachers of school (for students' academic competencies).

$>$ School Information with head Teacher or teacher (about infrastructure at school).

The Structured Information Schedule for all was developed to assess the educational problems with respect to different types of CWSN. Observation of residential bridge course, primary school, special school for disabled children was done.

\section{Results and Discussion}

The present study examines the impact of environmental adjustment on elementary education of children with special needs on the basis of the responses of the children, parents, teachers, Head teacher on various issues. Frequencies of the responses of the different stake holder were grouped and different tables were prepared for analysis. SQL database was used for analysis.
Attendance: Regular attendance in school reflects students' interest in learning and whether school is adjustable in access and learning. Attendance of students is classified into 5 categories. ' $A$ ' for more than 80 percent attendance, ' $B$ ' for $60-80$ percent attendance, ' $\mathrm{C}$ ' for $40-60$ percent attendance, ' $\mathrm{D}$ ' for less than 40 percent attendance.

Adjustment at home: This is one of the most important areas of study to see how children adjust with personal, public and school environment, and if it has any impact on their attendance and learning.

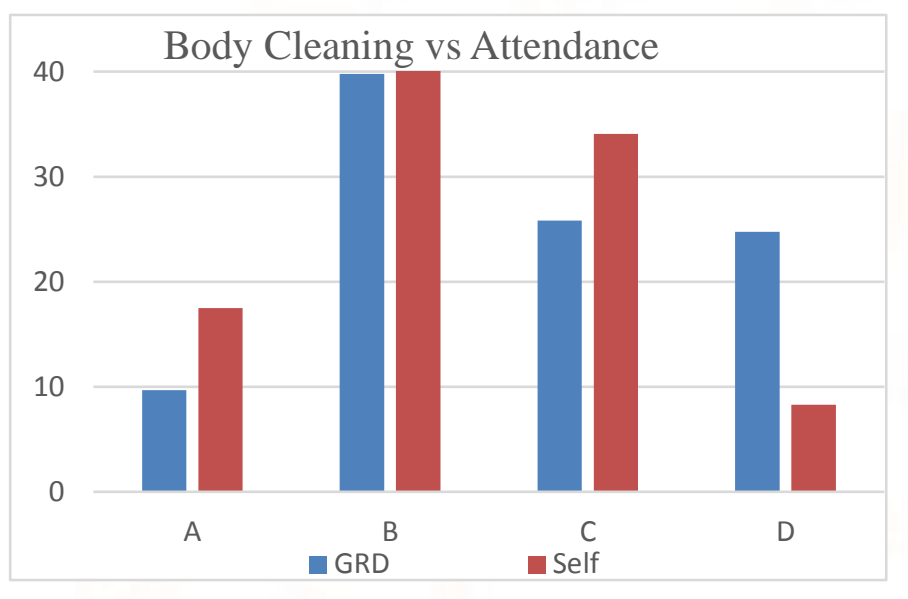

Figure 1 : body cleaning

In the given graph 'GRD' means guardians and 'self' stands for children doing things themselves. Data shows that two-third of CWSN do body cleaning by themselves. Attendance of children less than 40 percent is more for students, who are not able to do their own care, and those, who may perform their own body cleaning at home has better attendance at school. Means those, who physically adjust better at home has higher attendance level at school, because they have confidence of managing their own things, independently.

Routine Outing Vs Attendance: There are many children, who adjust with outside environment and move comfortably in roads, parks, market places, neighbours' building etc., such children enjoy high confidence level due to adjustment.

Data analysis shows that disabled children, one-third of CWSN taken in sample needs guardian help in movement. Majority of CWSN whose attendance is less than 40 percent at school are those who need guardian help in movement, while those who may freely move around their village, campus, home on their own have significantly greater chances of attending school regularly. Means those can easily 
adjust with environment, with respect to movement with the help of equipment or without equipment results in better attendance at school. Moving around built confidence of adjusting with environment even of more difficult terrain.

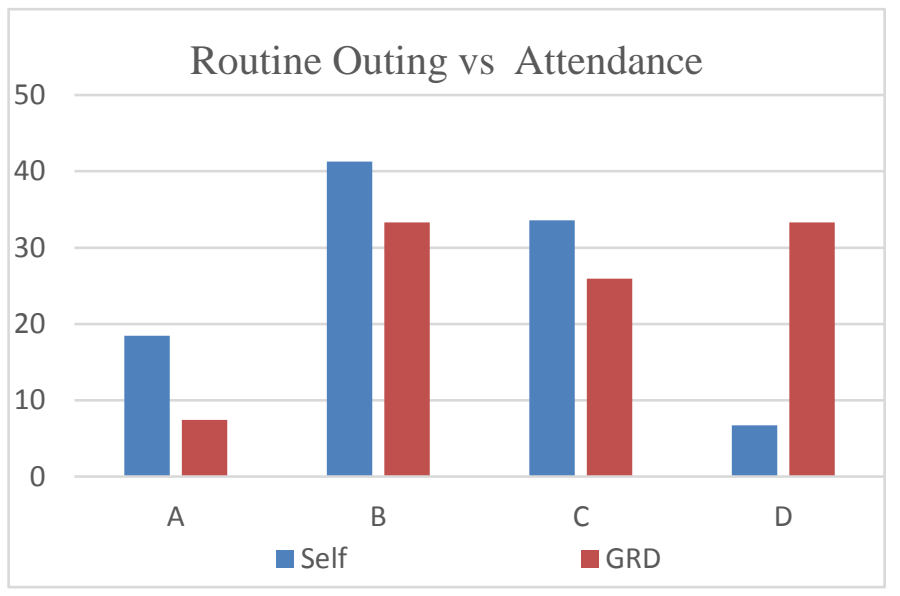

Figure 2: Routine outing impact

Daily routine work Vs attendance (Adjustment): there are so many routine work a child has to do to adjust at home, like taking water and food, arranging his belongings, arranging his/her toys, setting cloths, bathing, and obeying mother/father instruction.

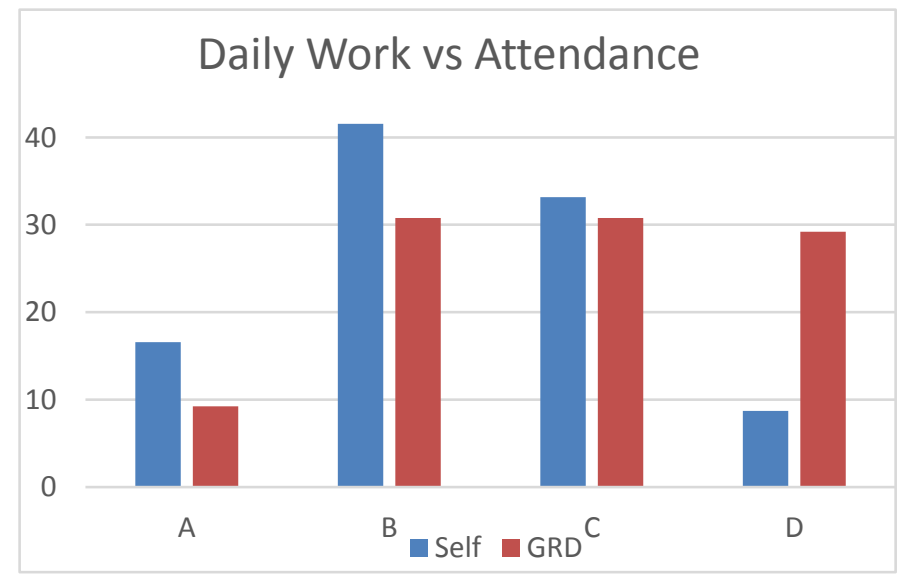

Figure 3

Data analysis gives a significant correlation between children adjusting with routine work and their attendance. Every one-fifth CWSN taken in sample cannot perform their daily work independently. Those, who may easily perform their work at home, have enough adjusting skill to perform their job at school or other places. This confidence of performing, if praised from time to time boost their energy level to even perform better.
Participation at social function: Participation at social function may be an event of choice for every child. During study we found that due to teasing and taunting disabled children generally avoid social function but participate in family function. Let's see do adjustment at social function has any relation with attendance at school for CWSN participation in functions Vs attendance

\section{Figure 4}

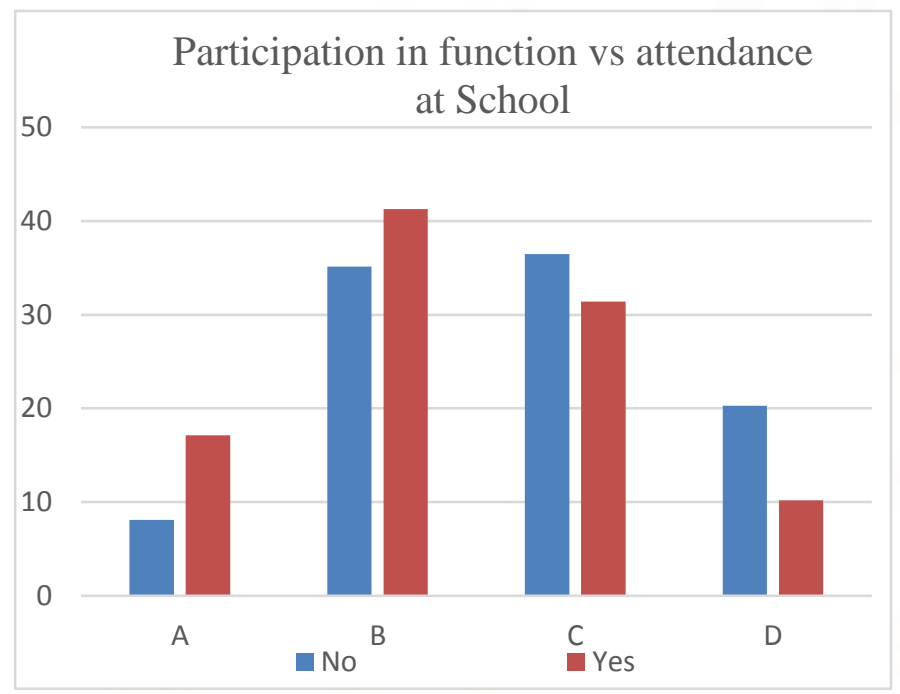

Data shows every one-fifth CWSN do not go to attend social or family function due to social construct or family construct. In study it was mentioned by family that such children are problem at function because they need extra care. Even other feel that such children should be kept way because they cannot enjoy the function due to large gathering and no time with parents or others to take care of them.

Data shows positive correlation between children attending such function and attendance at school. Means those children, who may adjust at functions will adjust at school or those who have ability to adjust at school will go to functions because they have higher confidence level of adjusting.

Play out outdoor games: Children love to play game and go outside for the purpose. CWSN have a little difficulty in adjusting with every game. So they play game, which are adjustable or in which their disability doesn't matter. Let's see how adjusting skill with games impact their attendance at school. 
Figure 5: Playing games and attendance at school
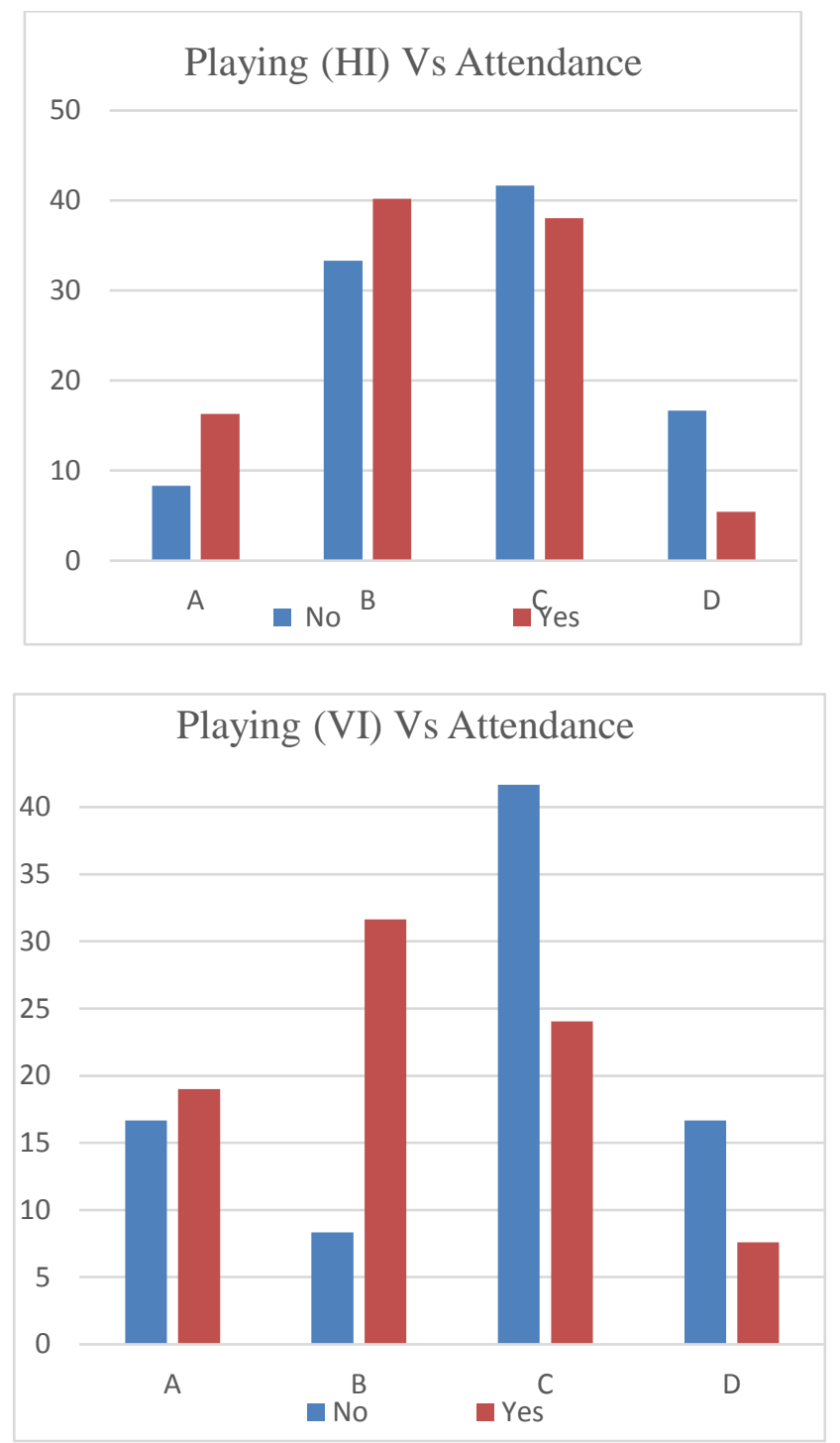

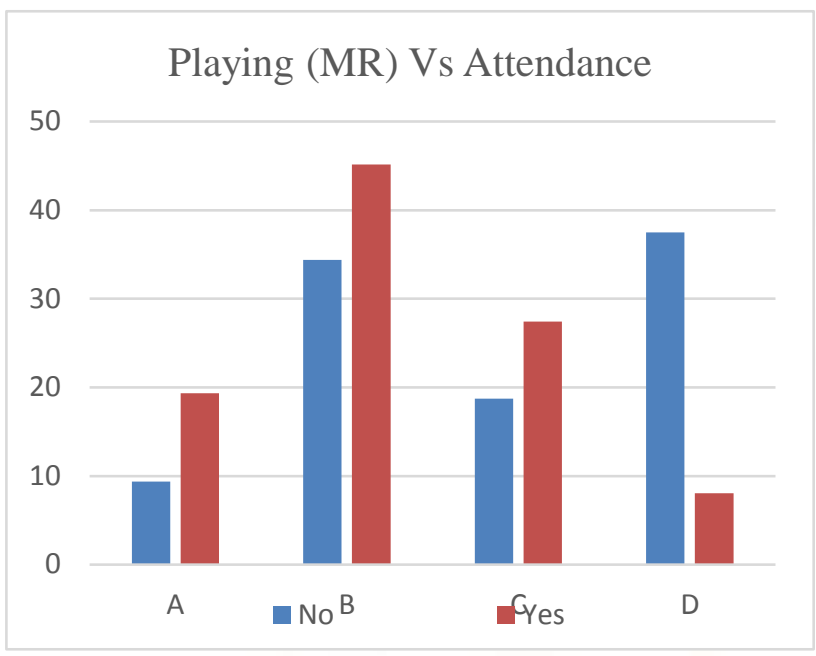

Playing $(\mathrm{OH})$ Vs Attendance

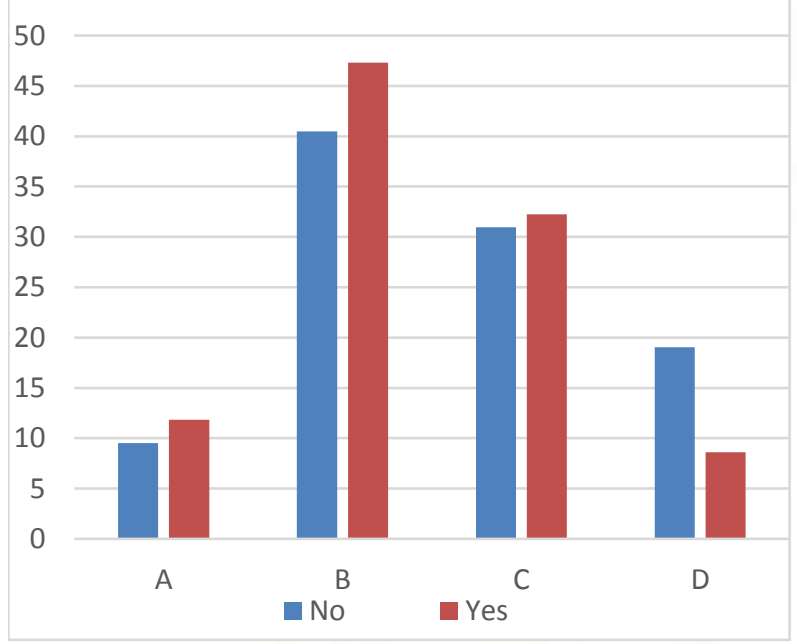

Data show that every one fifth of VI and HI CWSN don't play out door games, while one third of $\mathrm{OH}$ and MR CWSN don't play outdoor games. Data shows positive correlation between playing and school attendance. Playing game require children to adjust to so many physical and mental challenges. Children, who may adjust their mental and physical condition for play, will do the same in other situations in case of requirement. Playing at school should be encouraged to train children to adjust with different kind of mental and physical conditions. This kind of activity will make them mentally strong, even to face social evil of teasing and taunting.

\section{Adjustment with equipment:}

There are some disabilities, whose impact may be minimised with the use of certain equipment, specially constructed for the purpose. Orthopedically disabled children may adjust better with environment with the help of callipers, baishakhi, wheel chair etc. Hearing impaired children may adjust better with hearing aid machine; visually impaired children may adjust better with cane, brail slate and abacus. Let's see, how adjustment with equipment results in attendance. 


\section{Figure 3: Availability of equipment and Attendance}

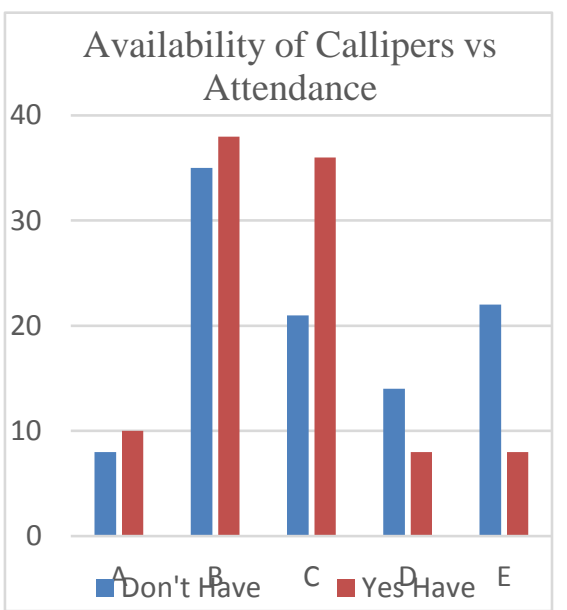

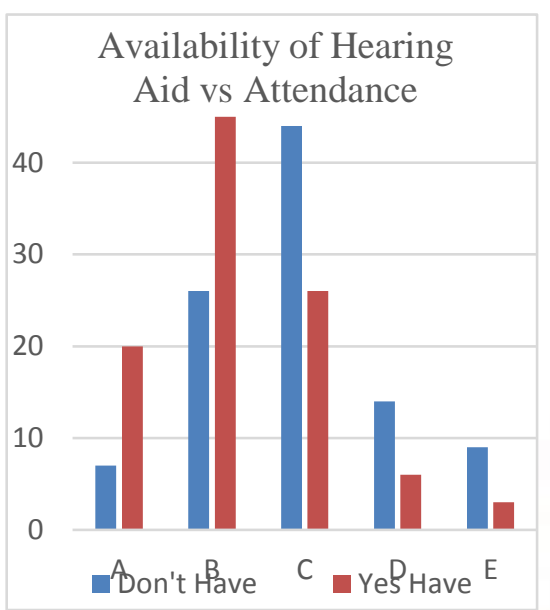

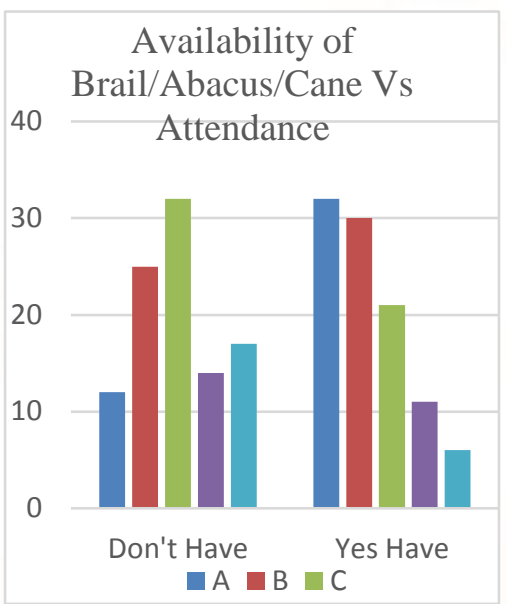

Data shows that there is a positive correlation between attendance of disabled children and use of equipment for adjustment. It also shows that a very large number of disabled children do not have equipment to adjust with the environment. Data also shows that orthopaedic children attendance improvement is not as significant as in two other disability type say hearing and visual. Most significant improvement is visible in visually impaired children. Learning of visually impaired children improves significantly and they start responding quickly due to new method of writing and reading called brail. So adjusting with environment with equipment or instrument improves student's attendance.

\section{Adjustment to equipment:}

It is not an easy task to adjust to equipment; it needs to be as per requirement of children. Sometime due to faulty measurement or technical problem equipment becomes useless. During field survey we found a lot of orthopedically and hearing impaired children not using their equipment, we were informed that child is uncomfortable with given equipment. Sometime children have not been given proper training for using equipment, so equipment become useless.
Data shows that it is very easy for visually impaired children to adapt knew abacus, brail writing method, and using cane. There are some children, who don't have equipment but they know, how to use it from their peers because they need it, so learning is a need for them for life.

It seems that it is difficult for children to adjust with callipers; it may be due to design, technical issue, and training. During study we encountered so many children who were not using their equipment, because they are unable to adjust with the device.

Since hearing aid is easy to adjust, parent, child can be easily made aware of the process of use. It's fascinating to know that even children, who don't need this device learn quickly, how to use, some of the children, who want this device but do not have, learnt its operation from their peers.

\section{Conclusions and Recommendations}

The overall study elucidates the issue of disabled children and over all need on bringing out findings, recommendations and suggestions for further research that has emerged out of the analysis and interpretation of data is presented. 

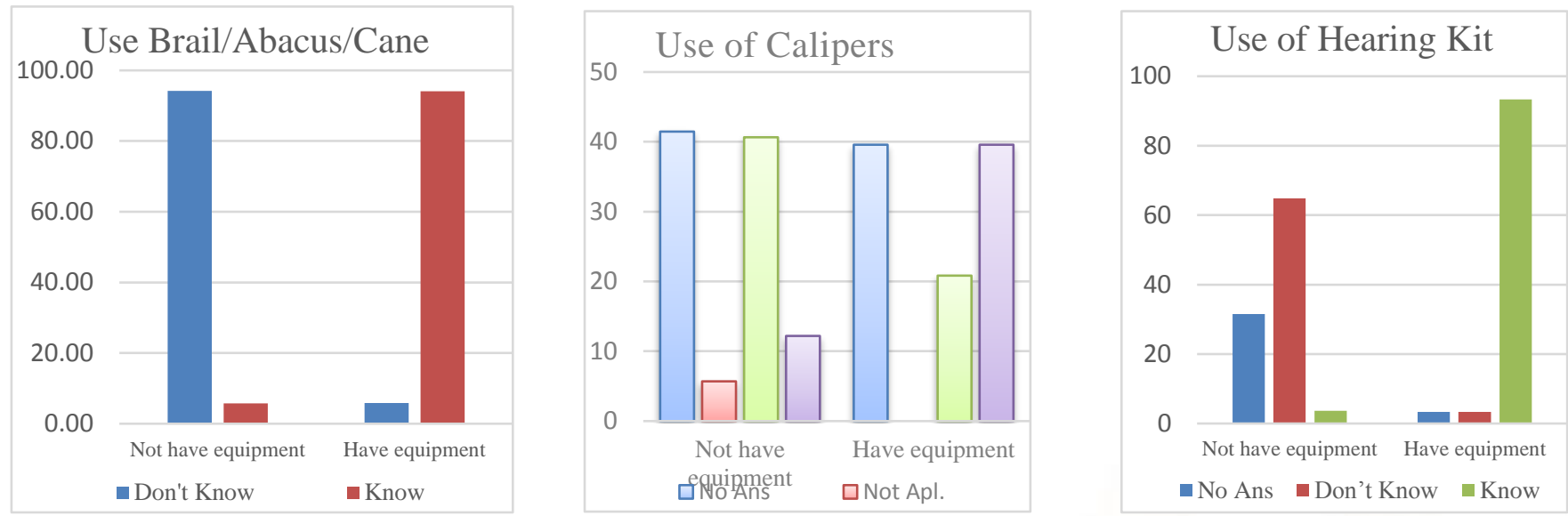

Implication of adjustment on disabled children education

CWSN, who do their own cleaning at home have better attendance at school. Adjusting better at home might have put them on higher confidence level, so they may manage their own things outside home.

CWSN, who freely move around their village, campus, home have significantly better attendance at school. Means those, who can easily adjust with environment, with respect to movement with or without equipment have better attendance at school. Ability and opportunity to move around construct confidence of adjusting with even new difficult situation.

There is a significant correlation between children adjusting with routine work and their attendance. Means those, who can easily perform their work at home, have enough strength to perform at school or other places. This confidence of performing, if praised from time to time may boost their energy level to even perform better.

$>$ There is a significant number of disabled children do not attend social or family function due to social construct and family construct. In study it was mentioned by family of CWSN that such child is problem at functions, because he/she needs extra care. Even other people also feel that such children should be kept away because they cannot enjoy the function due to large gathering and no time with parents or others to take care of them.
Positive correlation has been found between children attending family function and attendance at school. Means those children, who may adjust at any function will adjust in school or those who have ability to adjust at school will go to functions because they have higher confidence level of adjusting.

There is positive correlation between playing games and school attendance. Playing game require children to adjust to so many physical and mental challenges. Children, who may adjust their mental and physical condition for game, will adjust in the same way at other places in case of requirement. Playing at school should be encouraged to train children to adjust with different kind of mental and physical conditions. This kind of activity will make them mentally strong, even to face social evil of teasing and taunting.

There is a positive correlation between attendance of disabled children and use of equipment for adjustment. It also shows that a very large number of disabled children do not have equipment to adjust with the environment. Data also shows that orthopaedic children attendance improvement with adjustable equipment is not as significant as in other two disability type say hearing and visual.

Most significant improvement in learning achievement is visible in visually impaired children. Learning of visually impaired children improves significantly and they start responding quickly due to new method of writing and reading called brail. So adjustment with new equipment and material improves student's attendance. 
It is very easy for visually impaired children to adapt and learn new reading writing script known brail, they also adapt new adjustable equipment like: cane for movement. There are some children who don't have equipment but they know how to use it from their peers because they need it, so learning is a need for them.

Hearing aid is easy to adjust, parent, children can be easily educated in its use. It's fascinating to know that even children who don't need this device learn quickly.

Students should be trained, how to use these appliances, most of the time non training and apathy of teachers' make aids and appliances a useless device and children doesn't go to school for fear of answerability.

Every aid and appliances have their own life, so these items should be provided periodically in case of need. Children should be given opportunity to learn new skills and do their things on their own, that will make them feel confident. Children must also be counselled to feel their own specialty and identity.

Sometimes low-tech or less-sophisticated devices will meet CWSN needs. Such simple accommodations as big books, preferential seating, behaviour-management programs, or modified desks may be sufficient for many children with disabilities.

\section{Bibliography}

1) Angela, Kohama: Inclusive education in India a country in transition (June 2012).

2) Balasundaram, Pramila. The Journey to words inclusive education in India, 9th July 2005.

3) Dr. Karen, Walker. University of Maine, Farmington: inclusive model for students in special education: union pacific foundation. Web address- www.principalspartnership.com

4) Dr. Kumar, Sanjeev \& Dr. Kumar, Khagendra. Inclusive Education in India: Electronic Journal for Inclusive Education, 2007.

5) Geoff, Lindsay. Educational psychology and the effectiveness of inclusive education/ mainstreaming: university of Warwick, UK, British journal of educational psychology, 2007.
6) Griffin, Teresa. Children with Special Educational Needs, Information Booklet for Parents, the USAA educational foundation.

7) Hegarty, Seamus, and Mithu Alur. Education and Children with Special Needs: From Segregation to Inclusion. Thousand Oaks, Calif: Sage Publications, 2002.

8) Jangira, N.K. "Special Educational Needs of Children and Young Adults: An Unfinished Agenda," Education and Children with Special Needs: From Segregation to Inclusion, Ed. Seamus Hegarty, Mithu Alur, Thousand Oaks: Sage Publications Inc., 1997. Print.

9) Jayne, Pivik. Joan, Mccomas. Marc, Laflamme. Barriers and Facilitators to Inclusive Education: university of Ottawa, Canada, council for exceptional children, 2002, vol. 69, pp. 97-107.

10) Kalyanpur, Maya. "Equality, Quality and Quantity: Challenges in Inclusive Education Policy and Service Provision in India." International Journal of Inclusive Education.

11) Katharine, Giffard-Lindsay. Inclusive education in India: interpretation, implementation, and issues: consortium for reseach on educational access, transitions and equity, 2007.

12) Robyn, Stark. University of Canterbury, Diane Gordon-Burns, University of Canterbury, Kerry Purdue, University of Canterbury, Benita Rarere Briggs, University of Canterbury, Karen Turnock, University of Canterbury. Other parents' perceptions of disability and inclusion in early childhood education: Implications for the teachers' role in creating inclusive communities.

13) Sharma, Mahashram. The leap towards inclusive education: experience from Nepal: ministry of education and sports, department of education, Nepal, 2007.

14) Wesley, Sharpe, Ed.D. The characteristics of effective inclusion, 2005.

15) Shigeki, Fujii. Lifelong support through education, welfare, healthcare, Labor and Medical care (Consideration from the view point of the support system for Individuals with special needs by a local government)

16) Hasselbring, S. and candyce h. Williams Glaser. Use of computer technology to help students with special needs: The Future of Children: Children and Computer Technology, vol. 10 ted, 2000. 